\title{
The Major Causes of Death in the Army and Comparisons with the Civilian Population
}

\author{
Major T P Finnegan, MSc, AFOM, RAMC \\ Medical Branch, $H Q$ Ist British Corps
}

\section{T L C Lewis, BA}

Medical Statistics Branch, Ministry of Defence

SUMMARY: Statistics of 881 British Army male non-operational deaths between 1980 and 1984 were analysed and comparisons made with civilian mortality for certain categories of deaths. Disease accounted for $32 \%$ and injury for $68 \%$ of the deaths. Road traffic accidents (RTAs) comprised $\mathbf{4 0 \%}$ and ischaemic heart disease (IHD) $13 \%$ of the total. The overall Standardised Mortality Ratio (SMR) was 92. By comparison with the UK civil population serving members of the Regular Army suffered considerably less from disease deaths (SMR 58) with the exception of IHD (SMR 92), but more from injury deaths (SMR 135). RTA deaths had an SMR of 200. The review suggests that attention should be directed towards incidents causing RTAs and drowning. Action taken in peace may have relevance to survival on operations.

\section{Introduction}

Each year a considerable number of serving Regular Army personnel die. Over the 5 year period 1980 to 1984 there were 881 non-operational deaths, 282 from disease and 599 resulting fron injury. An average of 176 deaths each year represents a substantial loss of human resources. The Army has built up a reputation as a good employer which is based partly upon the care with which it looks after its soldiers. Deaths are newsworthy events and it is important that bad publicity does not occur because of unnecessary loss of life. Such comment would erode the good standing of the Army. The Army's reputation was made before the Health and Safety at Work Act 1974 but such legislation gives increased importance to an employer's responsibilities for his workforce.

From the Army's point of view deaths cause a loss of manpower, often skilled, which is not always easily or quickly replaced. Each death may also involve considerable financial outlay in the form of pension, particularly if the death was attributable to the Army service.

To be able to illustrate the Army's position on the one hand and to monitor and improve prevention on the other, adequate knowledge of how deaths occur must be available. Without such information comparisons and action can be based upon no more than gut-feeling and guess-work.

Of the 150 to 200 non-operational deaths that occur each year many are likely to be deemed unavoidable within the parameters of a normal life. There will be, however, a number of deaths which are preventable, given the better application of sensible and generally well-known rules.

\section{Data}

Information on the number and circumstances of Service deaths is collected by the Tri-Service Medical Statistics Branch (Med Stats) of the Ministry of Defence (MOD) at Stanmore where it is recorded and analysed. Summary figures are published in the annual Defence White Paper (Statement on the Defence Estimates, Vol
2). Five-yearly summaries for the years $1976-80$ and 1979-83 were published in 1983 and $1986^{1}$. Med Stats has more recent and detailed information available on request.

Data for 1980 to 1984 are presented in this paper concentrating on male Regular Army personnel. The period selected for review is that for which the moston? recent full figures, analyses and calculations of age- 0 standardised mortality ratios were available.

\section{Cause of Death}

Table 1 shows the deaths of British Army males for the years 1980 to 1984 . The major division of deaths is between those due to disease and those due to injury. Injuries accounted for $68 \%$ of total non-operational deaths. Road traffic accidents (RTAs) were the largest category with $40 \%$ of the total. Among diseases, ischaemic heart disease (IHD) is the largest single category accounting for $13 \%$ of the total.

The numbers of deaths in relation to the total strength of the Army are small as indicated by the death-rates shown in Table 2. During the review period, with the obvious exception of 1982, the year of the Falklands Campaign, the Army's death-rate has declined marginally. This applies to both diseases and injuries.

\section{Comparisons with Civilians}

The figures in Table 1 give no indication of how the Army compares with the civilian population. Some causes of death have no civilian counterpart. Other categories, while of importance to the Army, may not be of such importance to the general population.

The Standardised Mortality Ratio (SMR) is a convenient way of making comparisons. This ratio shows the actual mortality of personnel dying whilst serving in the Armed Forces as a proportion of the expected rate and is calculated by applying observed civilian mortality rates to the Armed Forces population divided into appropriate (in this case 5 year) age groups. Comparisons of death-rates with civil life are bound to 
Table 1

British Army Males: Number of deaths 1980-1984

\begin{tabular}{|c|c|c|c|c|c|c|c|}
\hline Description of cause of death & 1980 & 1981 & 1982 & 1983 & 1984 & Average 1980-84 & Proportions \\
\hline All causes & 192 & 201 & 334 & 165 & 162 & 211 & - \\
\hline All non-operational causes & 185 & 191 & 192 & 160 & 153 & 176 & $100 \%$ \\
\hline All diseases & 55 & 68 & 59 & 54 & 46 & 56 & $32 \%$ \\
\hline Ischaemic heart disease (IHD) & 24 & 26 & 23 & 20 & 18 & 22 & $13 \%$ \\
\hline Other diseases & 31 & 42 & 36 & 34 & 28 & 34 & $19 \%$ \\
\hline All non-operational injuries & 130 & 123 & 133 & 106 & 107 & 120 & $68 \%$ \\
\hline Road traffic accidents (RTAs) & 80 & 78 & 72 & 58 & 61 & 70 & $40 \%$ \\
\hline Other injuries & 50 & 45 & 61 & 48 & 46 & 50 & $28 \%$ \\
\hline
\end{tabular}

be affected by the selection which members of the Army undergo on entry and, subsequently, through medical boards which may result in a medical discharge. The most important parts of the selection, in this context, are the medical examination and basic training. The former is designed to select out those pre-disposed to illness, while the latter selects out those with poor motivation.

The most widely publicised figures show the Armed Forces in a poor position. The Office of Population Censuses and Surveys' (OPCS) figures ${ }^{2}$ do not break down the Armed Forces into the single Services. The overall SMR given for all of them was 147 . That is, the Armed Forces has an observed death-rate $47 \%$ greater than would be expected when compared with the UK population and allowing for differences in age structure.

Blackburn $^{3}$ examined the figures and calculated for the period 1974 to 1977 an SMR for the Armed Forces of 95 and for the Army alone one of 115 , with deaths from disease having an SMR of 67. The difference occurs because death certificates often record the Armed Forces as the occupation even though the deceased may have retired from the Services and taken up other

Table 2

British Army Males: Death-rate per 1000 men serving

\begin{tabular}{llllll}
\hline Description of cause of death & $\mathbf{1 9 8 0}$ & $\mathbf{1 9 8 1}$ & $\mathbf{1 9 8 2}$ & $\mathbf{1 9 8 3}$ & $\mathbf{1 9 8 4}$ \\
\hline All causes & 1.23 & 1.25 & $\mathbf{2 . 1 4}$ & 1.07 & 1.04 \\
\hline All non-operational causes & 1.19 & 1.19 & 1.23 & 1.04 & 0.98 \\
\hline All diseases & 0.35 & 0.42 & 0.38 & 0.35 & 0.30 \\
$\begin{array}{l}\text { Ischaemic heart disease } \\
\text { (IHD) }\end{array}$ & 0.15 & 0.16 & 0.15 & 0.13 & 0.12 \\
Other diseases & 0.20 & 0.26 & 0.23 & 0.22 & 0.18 \\
\hline All non-operational injuries & 0.83 & 0.76 & 0.85 & 0.69 & 0.69 \\
$\begin{array}{l}\text { Road traffic accidents } \\
\text { (RTAs) }\end{array}$ & 0.51 & 0.49 & 0.46 & 0.38 & 0.39 \\
Other injuries & 0.32 & 0.27 & 0.39 & 0.31 & 0.30 \\
\hline
\end{tabular}

employment. To qualify and illustrate the difference there were, according to OPCS, 1,858 deaths of Armeक्षे Forces personnel in England and Wales between 197ক, and 1972, an average of 619 per year. MOD figure covering the same period show an average of 521 deaths per year for serving personnel worldwide.

Med Stats have calculated SMRs for British Armis males aged 20-54 for 1980 to 1984 (Table 3). The ovepald SMR for non-operational deaths is 92 . For diseases if is. 58. The important point to note is that the 'all diseasis' SMRs by age group are all below 100 . This is as wouldite expected because of the selection of Army personifef and confirms the Army's favourable position. Howege one figure of importance is the SMR for ischaemic heart disease in the Army of 92 . This indicates that incidence of IHD fatalities is less than occurs in the population but it is still much greater than the SMR ofte for other diseases in the Army. For non-operationas injuries the overall SMR is 135 and, in contrast to thos for diseases, it is much higher for the youngest age्ष groups and it only falls below 100 for 2 age groups. Thi $\mathbb{Q}$ indicates where preventive action in peacetime should be directed and should prove to be of value. The very high RTA SMR figure of 200 indicates the Army's majo르 problem. The SMR of 93 for other injuries excluding. RTAs and operational injuries, indicates that there is not an excess mortality.

\section{Ischaemic Heart Disease}

Ischaemic heart disease (IHD) has been the singlo largest cause of death from disease in the Army.

Lynch and Oelman ${ }^{4}$ reviewed the position for men under 55 years for the period 1973 to 1977 . There weri 148 cases in the 5 year period. The IHD SMR was 100 i.e. comparable to the incidence among the UK males population allowing for the different 'mix' of ages, bu? considerably in excess of the all diseases SMR of 67 for the Army. SMR's were calculated separately for officers and for soldiers. The IHD SMR for officers was 54 and that for soldiers 148 . As would be expected in broad terms the Army follows the pattern of coronary heart 
Table 3

British Army Males: Standardised Mortality Ratios 1980-1984 inclusive

\begin{tabular}{lcccccccc}
\hline $\begin{array}{c}\text { Age Group } \\
\text { Cause of Death }\end{array}$ & $\mathbf{2 0 - 2 4}$ & $\mathbf{2 5 - 2 9}$ & $\mathbf{3 0 - 3 4}$ & $\mathbf{3 5 - 3 9}$ & $\mathbf{4 0 - 4 4}$ & $\mathbf{4 5 - 4 9}$ & $\mathbf{5 0 - 5 4}$ & $\begin{array}{c}\text { TOTAL } \\
\mathbf{2 0 - 5 4}\end{array}$ \\
\hline All non-operational causes & 130 & 96 & 75 & 89 & $\mathbf{7 3}$ & 59 & 44 & 92 \\
All diseases & $\mathbf{5 8}$ & $\mathbf{4 5}$ & 51 & 89 & 63 & 53 & 41 & $\mathbf{5 8}$ \\
IHD & 110 & 235 & 98 & 169 & 81 & 70 & 47 & 92 \\
Other diseases & 56 & 31 & 42 & 57 & 51 & 40 & 37 & 46 \\
All non-operational injuries & 162 & 132 & 102 & 90 & 106 & 105 & 85 & 135 \\
RTAs & 215 & 177 & 188 & 133 & 193 & 253 & 190 & 200 \\
Other injuries & 106 & 107 & 68 & 76 & 81 & 67 & 56 & 93 \\
\hline
\end{tabular}

disease found in the civil population. That is, there was an inverse relationship between socio-economic group and mortality.

Particularly interesting and relevant was that Servicemen aged less than 40 (almost all soldiers) had a significantly higher IHD mortality ratio than the highest mortality ratio of the civilian social classes - Class V, unskilled occupations. Lynch et $a l^{5}$ examined the risk profile and concluded that heavy cigarette smoking was the major discriminating factor in soldiers under 40 with coronary heart disease.

Studies by Lynch ${ }^{6}$ and Lynch $e t a l^{7}$ indicate that any connection between physical exercise and IHD death was coincidental. These studies spanned the period when the compulsory Basic Fitness Test was introduced. The slight increase in the incidence of mortality from 2.2 to 2.5 per 100,000 man-years pre- and post- 1977 was probably related to a generally increased involvement in exercise. In this context it is worth bearing in mind that the Army does not exist primarily to produce healthier soldiers, but to be an efficient military force.

\section{Road Traffic Accidents}

RTAs constitute a large category of deaths and caused $40 \%$ of all non-operational deaths between 1980 and 1984 among British Army males; the SMR was 200. In addition to the normal complexity of causes of RTAs there are a number of factors specifically related to Army life. These factors put the excess SMR into perspective but should not be reason for complacency. Firstly, the nature of Army life tends to lead personnel to travel more. Secondly, the percentage of car owners is probably higher than in the general population. Thirdly, the accident rates on continental Europe are higher than in the UK. About one third of the Army is posted there and two-fifths of its RTA deaths occurred there.

Alcohol has been implicated as being of considerable significance in causing RTA's. Figures are extremely difficult to find. Lynch in his seminal paper ${ }^{9}$ has shown that the incidence of alcohol associated death in RTAs between 1968 and 1977 was the same in the UK and BAOR for off-duty male Regular Army personnel. His criterion for alcohol association was a blood alcohol concentration of $80 \mathrm{mgs} / 100 \mathrm{mls}$. Of the RTAs studied $30 \%$ had had a blood alcohol concentration measured.

An important area for future research is to ascertain the blood alcohol concentration of those $70 \%$ RTA deaths where no alcohol estimation was made. The information available to Med Stats concerning alcohol in relation to RTA deaths is scanty and imprecise. The figures do not identify alcohol as a causative factor butto record those cases where alcohol has been mentioned in: the report received, however incidentally. Further examination would be required before they could be published.

\section{Other Fatal Injuries}

Deaths due to other injuries have a wide variety of $\overrightarrow{0}$ causes. One group which does not fit neatly into the ${ }^{\infty}$ standard International Classification of Disease (ICD) but which can be identified from the NATO cause of injury codes applied by Med Stats, is death occurring during military training and exercises. These deaths are classified as accidental injuries arising during:

a. Schemes and exercises.

b. All other scheduled training (including basic training).

These deaths (Table 4) may be regarded as the 'acceptable risk' of military training, but deaths during military training frequently attract comment in the press. Such comment is generally well balanced and not overly critical of the Army, and because of this it may appear that the rate of deaths is not unduly high. This should not however lead to complacency because many training deaths may be preventable.

As would be expected, land transport accidents, which include on-duty RTAs, are the major cause of 'training and exercise' fatalities. Fatigue is likely to be an important factor particularly with the increased emphasis upon a 24-hour battle with limited opportunity for adequate rest. Four out of every five land transport deaths during military training occur while on 'schemes and exercises' rather than during 'all other scheduled training'. Commonsense would seem to indicate that fatigue is likely to be greater in the former. 
A most important finding of a study on Sports Injuries in the Services between 1969 and 1980 by Tointon ${ }^{8}$ was that half of the deaths were caused by drowning and occurred during swimming, diving or boating. Between 1980 and 1984 there were 35 non-operational deaths in the Army attributed to drowning; 20 occurred off-duty and 15 on-duty. Alcohol was involved in about one third of these off-duty incidents according to the information reported to Med Stats.

\section{Scope for Prevention}

The scope for preventing avoidable deaths has 2 main limitations - knowledge and will. Med Stats hold an enormous amount of computerised information but generally they are restricted to responding to specific questions rather than to identifying problem areas.

The Army Medical Services (AMS) receive the small routine output from Med Stats. Although this is obviously appropriate, many of the actions required to prevent Army deaths lie outside the control of the AMS. The necessary will to tackle the problems must emanate from the executive branches. These, however, cannot act unless they are aware of the problems. Better coordination between statistical, medical and executive branches is required.

Even if both knowledge of a problem and the will to do something about it are present, the necessary action will involve changes in lifestyle in many cases. The modern attitude is that each individual should decide for himself how he wishes to live provided he is within the law. The Army, however, has at least two reasons for trying to influence the lifestyle of its soldiers in this context. Firstly as an employer, with a special and traditional responsibility for the health and welfare of its employees, and secondly to enhance the military efficiency of the Army as a whole.

Death has been chosen as the subject of this paper because the availability and reliability of information about it is good and it is unlikely that instances are missed. The absolute number of deaths is small in terms of mortality statistics for the UK population as a whole, but still important to a relatively small Army. Deaths may also be viewed as an easily identifiable part of a bigger problem like the tip of an iceberg. That is, for every death there are likely to be several serious injuries, many minor ones and multiple near-misses. Death can

Table 4

British Army Personnel: Deaths occurring during military training and exercises 1980-84

\begin{tabular}{lrrrrrr}
\hline Year & $\mathbf{1 9 8 0}$ & $\mathbf{1 9 8 1}$ & $\mathbf{1 9 8 2}$ & $\mathbf{1 9 8 3}$ & $\mathbf{1 9 8 4}$ & $\mathbf{1 9 8 0 - 8 4}$ \\
\hline Deaths & 16 & 13 & 17 & 10 & 16 & 72 \\
Rate (a) & 0.10 & 0.08 & 0.11 & 0.06 & 0.10 & 0.09 \\
\hline
\end{tabular}

(a) Number of deaths per 1,000 British Army personnel serving therefore direct attention to areas where further investigation is warranted. For example, RTAs quite apart from killing soldiers, cause large amounts of absence from duty and result in many medical discharges. The corollary is that action taken to prevento death is also likely to reduce the non-fatal aspects of the problem.

Operational Relevance
Prevention of death is essentially a peacetime activity. However preventive action in peace is likely to improve performance during operations.

Two examples from this review illustrate this point. o Firstly, fatigue is an inevitable part of military life. Action should however be taken to reduce it to a. minimum. An analysis of the cause of fatal accidents, $\overrightarrow{\vec{\omega}}$ particularly those involving vehicles during 'training and exercises', may bring out errors that were made in the $\overrightarrow{\mathbb{D}}$ management of fatigue. Learning, or more probably re- 3 learning, from such errors should reduce fatigue and its effects in all situations including operations.

Secondly, the number of deaths from drowning is surprisingly high. Further investigation in detail may reveal why this is so, but whatever the outcome of suक्षि an investigation, it is likely that the circumstances in 윽 peacetime will have been more favourable than woutg $\rightarrow$ be the case on operations when lifejackets may not available and when more equipment may have to carried. The ability to swim is a requirement for soldiers but it is not often practised in realisti circumstances. The implication is that more effectike $\overrightarrow{0}$ training would be of benefit in both peace and war.

\section{Conclusion}

The number of non-operational deaths in the Army is such as to merit continued analysis. Compared with civilian life the Army fares much better vis à vis deaths from disease with the major exception of IHD. However it sustains relatively more deaths from injury, particularly RTAs.

Military training causes its own group of deaths with drowning as a notable sub-group. However physical exercise per se does not appear to be an important factor.

Changes in life-style such as reducing alcohol intake and cigarette smoking may well be necessary to achieve a substantial lowering of the number of deaths.

\section{REFERENCES}

1. Statistical Tables on the Health of the Army 1976-1980 and Report on the Health of the Army 1979-1983. London: Ministry of Defence.

2. OfFice of Population Censuses and SuRveys (OPCS). Occupational Mortality 1970-1972. London: HMSO 1978.

3. Blackburn P J. Occupational Mortality in the Armed Services. J Soc Occup Med 1982; 32(1): 15-19. 
4. LyNCH P and Oelman B J. Mortality from Coronary Heart Disease in the British Army compared with the Civil Population. Br Med J. 1981; 283: 405-407.

5. LYNCH $\mathrm{P}$, et al. Risk profile of soldiers aged under 40 with coronary heart disease. Br Med J 1985; 290: 1968-1969.

6. LvNCH P, Soldiers, Sport and Sudden Death. Lancet 1980; 1: $1235-7$.
7. LYNCH P, et al. Sudden Death in Sport before and after the Introduction of the Basic Fitness Test. $J$ R Army Med Corps 1985; 131: 42-46.

8. Tointon J A. Sports injuries in the Services $1969-1980 J R$ Army Med Corps 1984; 130: 193-197.

9. LYNCH P. Alcohol Associated Deaths in British Soldiers. J R Army Med Corps 1987; 133: 34-36.

\section{ACADEMIC ACHIEVEMENTS}

FRCGP

FFOM Royal College of Physicians

MSc (Community Medicine)

DCH

LLB
Lt Col C Lyon-Dean, RAMC

Col P J Blackburn, L/RAMC

Major L H Lodge, RAMC

Major J D C Bennett, RAMC

Lt Col I T Houghton, RAMC

\section{CORRECTION}

On page 168 of the October 1987 issue of the Journal under "Academic Achievements" Major D K Brownhill RAMC and Major A Ghattas RAMC are listed as having passed FFARCS part I. Both of these Officers did, in fact, pass the Final part of FFARCS(I). The Editor apologises for this error, and wishes to congratulate the Officers on their achievement. 